\title{
Proliferating trichilemmal cyst of the scalp: Nine cases and literature review
}

\author{
ElBenaye $J^{1,3 *}$, Sinaa $M^{2,3}$, Elkhachine $Y^{1,3}$, Sakkah $A^{1,3}$, Jakar $A^{1}$ and Elhaouri $M^{1}$ \\ ${ }^{1}$ Department of Dermatology, Moulay Ismail Military Hospital, Meknes, Morocco \\ ${ }^{2}$ Department of Cytopathology, Moulay Ismail Military Hospital, Meknes, Morocco \\ ${ }^{3}$ Department of Medicine and Pharmacy, Sidi Mohammed Ben Abdellah University (USMBA), Fes, Morocco
}

\begin{abstract}
Background: proliferating trichilemmal cyst (PTC) is a rare adnexal tumor, primarily sitting on the scalp of elderly women. Its evolution is generally benign despite the rare malignant cases described. We report a series of 9 cases of which one is malignant and metastatic.

Material and methods: We retrospectively reviewed data of all patients with PTC seen at department of dermatology in the Meknes military hospital, between January 2013 and December 2017.

Results: Nine cases of PTC were diagnosed, which 8 in elderly women, with 62 years mean age. Trauma was found in one third of cases correlated with rapid growth of the tumor. The latter was symptomatic in $2 / 3$ of the cases. Ulceration involved only the malignant case. The size varied from 1,5 to $12 \mathrm{~cm}$. Recurrence after surgery was noted in 2 cases (malignant tumor and multi-cystic tumor).

Discussion: PTC appears to have a well-distinguished profile of the simple trichilemmal cyst. Some clinical and histological features may constitute prognostic factors of aggressiveness. Histological and immunohistochemical study is crucial in the management. A large excision remains the only guarantee of complete remission without recurrence or metastasis.
\end{abstract}

Conclusion: PTC remains misdiagnosed and very few series are reported. Prospective studies would allow the identification of prognostic factors of malignancy as well as better management.

\section{Introduction}

Proliferating Trichilemmal Cyst (PTC) is a rare adnexal tumor, derived from the isthmic portion of the hair follicle, mainly affecting the scalp of the elderly woman. Since description of the first case in 1966 [1], several observations are reported; most of them are cases report with literature review. Few series studying PTC are published. This is mainly due to the rarity of this condition but also to its slow and benign evolution, considered unattractive. However, malignant cases reported (about 50 in total) [2], suggested a renewed interest in PTC and should initiate serial studies to better understand this affection still enigmatic.

We propose our experience through series of 9 cases of PTC which one is a malignant variant. We would try to develop the different aspects (clinical, epidemiological, nosological, histological and therapeutic) of this entity, raising especially the difficulty of a prognostic prediction.

\section{Material and methods}

This is a retrospective observational study collecting cases of PTC of the scalp diagnosed at department of dermatology of Meknes Military Hospital between January 2013 and December 2017.

The diagnosis of PTC was clinically evoked and confirmed by histological examination. All patients with confirmed PTC sitting on the scalp were included. Epidemiological, clinical, histological and outcome data were collected and analyzed from complete medical records. The statistical analysis was done using Microsoft Excel 2010 software. Patients' consent to the use of their medical data for scientific research purposes as well as an agreement of the Ethics Committee was obtained.

\section{Results}

Over a period of 5 years, 9 cases are collected which 8 are women. Age average is 62 (37-72 years). Evolution of PTC ranges from 2 to 22 years with a median of 9.44 years. The notion of trauma is found in $1 / 3$ of the cases, always associated with a rapid growth of the tumor. PTC is symptomatic in $2 / 3$ of the cases: painful in 5 cases and itchy in one case. The ulceration concerned only the malignant case. The size ranges from 1.5 to $12 \mathrm{~cm}$ with a median of $4.5 \mathrm{~cm}$. Tumor's sit was on occipital and parietal region equally. PTC was evoked clinically, based on size of the lesion (Figure 1) and on macroscopic appearance (Figure 2). Histology confirmed the benignity in 8 cases while one case was malignant (Figure 3). No immunohistochemical complement was performed. Management of all cases was surgically, with a variable

*Correspondence to: ElBenaye J, Department of Dermatology, Moulay Ismail Military Hospital, 50000, Meknes, Morocco, Tel: +212 649281 889; E-mail: jalalelbenaye@gmail.com

Key words: trichilemmal cyst, proliferating, benign, malignant, histology, immunohistochemistry

Received: September 17, 2018; Accepted: October 15, 2018; Published: October 19,2018 


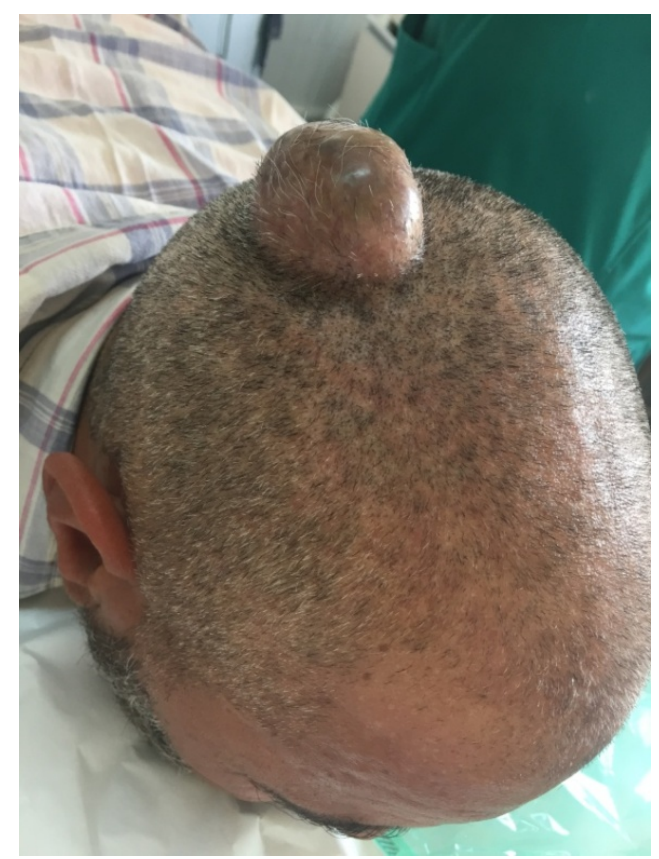

Figure 1. Clinical presentation of PTC

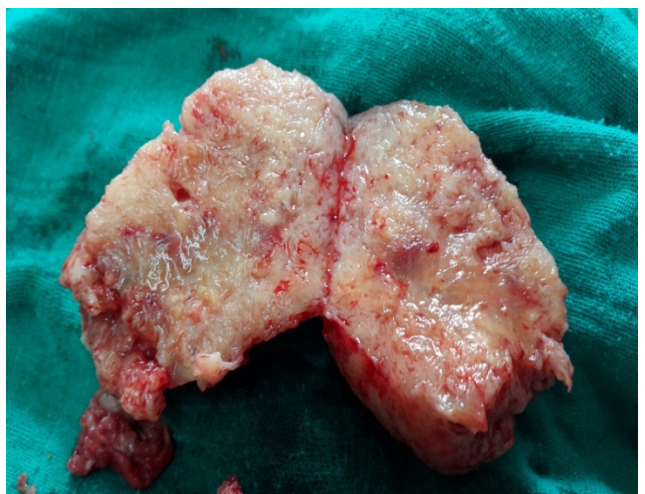

Figure 2. Macroscopic of PTC

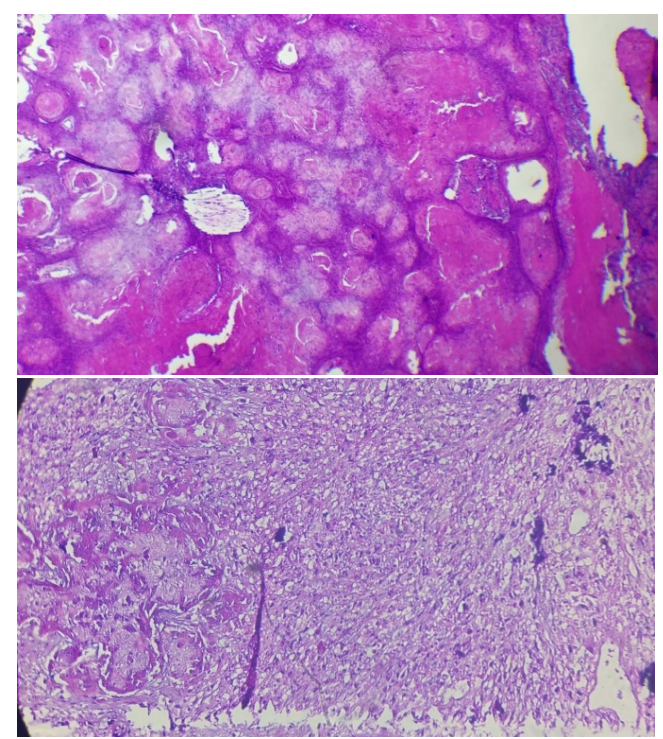

Figure 3. Histology of PTC. A) Benign PTC. Multilobular proliferative epithelial masses. $($ HE $\times 100)$. B) Malignant PTC. Trichilemmal keratinization with carcinomatous proliferation $(\mathrm{HE} \times 400)$ margin (enucleation up to $1 \mathrm{~cm}$ ). Recurrence after surgery was noted in 2 cases $(22.22 \%)$. Malignant form showed regional metastases without lymph nodes or distant metastases. Follow up was 12.33 months (5-30 months).

\section{Discussion}

Despite its small number of cases, this study remains among few series recently treated PTC $[3,4]$. It confirms preferential attainment of woman on the 6th decade. Scalp is privileged site of PTC. No real predominance of a region is seen even if occipital location; subject to more trauma; seems more frequently affected. Rarely, PTC could sit elsewhere, especially trunk $[5,6]$.

Classically, patient reports a slow evolution of a nodule which would grow up rapidly to $25 \mathrm{~cm}$ in diameter after trauma and could become painful and ulcer [7]. This latter, although present only in our patient with malignant PTC, does not appear to be a sign of malignancy since it has been described in several benign PTC $[8,9]$.

The role of pathologist is crucial in PTC management. It should specify diagnosis, benign or malignant nature and look for predictive histological factors that would condition therapeutic management. Complete excision is necessary. Histological study confirms characteristic trichilemmal keratinization. It would also appreciate architectural and cytological disorders that would differentiate simple trichilemmal cyst and PTC, although this distinction is not always obvious, especially in the early stages [7].

Histological findings could be confusing with squamous cell carcinoma (SCC); main clinical and histological differential diagnosis; especially of malignant PTC. However, absence of precancerous epidermal lesion such as actinic keratosis and absence of expression of monoclonal antibodies AE13 and AE14 would help to eliminate an SCC [2].

Immunohistochemistry may also solve riddle of benign or malignant PTC [10,11]. Presence of zones of necrosis with a strong mitotic activity and marked cytonuclear atypies could be providers of malignancy. However, for most authors, only clear infiltration of the stroma confirms this malignancy $[2,12]$. Benign PTC would strongly express CK10 and involucrin while in malignant form there would be a high number of cells expressing nuclear proliferation cell antigen and CK16 with loss of CD34 expression [2].

Prognosis of PTC is generally good. Only malignant cases are metastatic and can be life-threatening. Some authors have proposed a prognostic classification distinguishing 3 groups according to tumor architecture, degree of cytonuclear atypia, mitotic activity and angiolymphatic invasion, correlated with the potential for recurrence and metastasis [13]. This classification would be interesting to optimize therapeutic decision; however, it remains insufficient. Other prognostic factors should be considered: clinical (age, size, ulceration, lymph nodes), radiological (heterogeneous nature, intralesional necrosis, soft tissue invasion, bone erosion, distant localizations), histological (stromal infiltration, architectural asymmetry, marked atypia, cellular pleomorphism) and immunohistochemistry (ki67, cell proliferation nuclear antigen, CK16, CD34). In our cases, the only poor prognostic factor identified is malignancy of PTC.

Treatment of PTC is mainly surgical. A wide excision with $1 \mathrm{~cm}$ of lateral margin and deeply arriving at the periosteum is enough in benign cases or low grade of malignancy. This margin should be wider 
if tumor is predictive of a high risk of metastasis [2]. In some cases, radiotherapy and /or adjuvant chemotherapy based on Fluorouracil and Cisplatin are indicated with discussed efficacy $[2,14]$. Indeed, of the 39 cases of malignant PTC reported by Garg and al, 11 received radiotherapy and/or chemotherapy, 6 of them died after an average of 43 months [15]. In such cases, decision should be multidisciplinary.

\section{Conclusion}

PTC remains unknown by many practitioners because of its rarity that could be explained by the fact that it always escapes to histological study. Thus, any cyst of the scalp, as common as it appears, should be sent for histological analysis.

\section{References}

1. Jones EW (1966) Proliferating epidermoid cysts. Arch Dermatol 94: 11-19. [Crossref]

2. Elbenaye J, Elkhachine Y, Sakkah A, Sinaa M, Moumine M, et al. (2017) Malignant proliferating trichilemmal cyst of the scalp: A case report. Ann Chir Plast Esthet 67: 97-101.

3. Makiese O, Chibbaro S, Hamdi S, Mirone G, George B (2016) Huge proliferating trichilemmal tumors of the scalp: report of six cases. Plast Reconstr Surg 126: 18-19. [Crossref]

4. Sau P, Graham JH, Helwig EB (1995) Proliferating epithelial cysts. Clinicopathological analysis of 96 cases. J Cutan Pathol 22: 394-406. [Crossref]

5. Viarnaud A, Alhazmi K, Constant G, Gaudron S, Hirsch G, et al. (2017) Proliferating trichilemmal cyst. An unusual presentation. Ann Dermatol Venereol 144: 326-328.
6. Leyendecker P, de Cambourg G, Mahé A, Imperiale A, Blondet C (2015) 18F-FDG PET/CT Findings in a Patient with a Proliferating Trichilemmal Cyst. Clin Nucl Med 40: 598-599. [Crossref]

7. Bury Y, BloxhamC (2009) Proliferating trichilemmal tumour. Diagn Histopathol 15: 273-278.

8. Erdem H, Yildirim U, Uzunlar AK, Sahiner C, Ozcelik D, et al. (2011) Posttraumatic giant proliferating trichilemmal cysts on the parietal region of the scalp. Indian $J$ Dermatol Venereol Leprol 77: 707-709. [Crossref]

9. Mohamed M, Soua Y (2014) Giant proliferating trichilemmal cyst. Pan Afr Med J 18: 195. [Crossref]

10. Rangel-Gamboa L, Reyes-Castro M, Dominguez-Cherit J, Vega-Memije E (2013) Proliferating trichilemmal cyst: the value of ki67 immunostaining. Int J Trichology 5: 115-157. [Crossref]

11. Sleater J, Beers B, Stefan M, Kilpatrick T, Hendricks J (1993) Proliferating trichilemma cyst. Report of four cases, two with nondiploid DNA content and increased proliferation index. Am J Dermatopathol 15: 423-428. [Crossref]

12. Driss M, Bacha D, Mrad K, Charfi L, Abbes I, et al. (2007) Malignant proliferating trichilemmal tumor. Ann Pathol 27: 373-375.

13. Ye J, Nappi O, Swanson PE, Patterson JW, Wick MR (2004) Proliferating pilar tumors. A clinicopathological study of 76 cases with a proposalfor definition of benign and malignant variants. Am J Clin Pathol 122: 566-574. [Crossref]

14. Lobo L, Amonkar AD, Dontamsetty VV (2016) Malignant Proliferating Trichilemmal Tumour of the Scalp with Intra-Cranial Extension and Lung Metastasis-a Case Report Indian J Surg 78: 493-495. [Crossref]

15. Garg PK, Dangi A, Khurana N, Hadke NS (2009) Malignant proliferating trichilemmal cyst: a case report with review of literature. Malays $J$ Pathol 31: 71-76. [Crossref]

Copyright: (C2018 ElBenaye J. This is an open-access article distributed under the terms of the Creative Commons Attribution License, which permits unrestricted use, distribution, and reproduction in any medium, provided the original author and source are credited. 